\title{
How internal audit can champion continuous monitoring in a business operation via visual reporting and overcome barriers to success
}

\author{
Stacie Tronto. East Carolina University. USA trontos@ecu.edu \\ Brenda L. Killingsworth. East Carolina University. USA killingsworthb@ecu.edu
}

\begin{abstract}
Many auditing professionals would contend that continuous monitoring is a function of management and not internal audit. However, effective continuous auditing is highly dependent upon a strong continuous monitoring system. Further, by integrating technology of these two systems, continuous assurance can be achieved, and audit efficiency and effectiveness can be improved through the reduction of costs and effort. This paper discusses how internal audit can collaborate with a business operation to develop a continuous monitoring application utilizing visual reporting and overcome the potential barriers to success. The specific business operation selected for modification was the procurement card program at a large public university. Following an introduction of the scenario, an overview of the ProCard ${ }^{\mathrm{TM}}$ program is provided, highlighting the program risks and controls. Third, a four-phased approach used to develop the continuous monitoring tool is described, including specific steps taken to ensure effective use of the real-time data by auditors. Fourth, challenges the internal function encountered when implementing the system are described, including how those challenges were addressed. Fifth, the paper provides concluding comments and future initiatives planned. Finally, the paper provides additional examples for continuous auditing and monitoring and suggests future research topics in this area.
\end{abstract}

Keywords: Continuous auditing, continuous monitoring, visual reporting, internal audit, procurement card. 


\section{INTRODUCTION}

While it is uncommon for the internal audit function to champion a continuous monitoring project, such a project can enhance the capability of the internal audit function to fulfil its primary purpose. This paper describes the rationale and process undertaken to implement such a project, including why the internal audit function chose visual reporting and how the staff obtained the knowledge and skillset to build a continuous monitoring application. The specific case reported explains how the Internal Audit Department of a large public university implemented continuous monitoring in a business operation by utilizing visual reporting while overcoming common barriers to a successful implementation. The efficiencies and improvements obtained by the collaboration are also discussed.

\subsection{The Relationship Between Continuous Monitoring and Continuous Auditing}

Many auditing professionals would argue that continuous auditing is a function of the internal audit function and that continuous monitoring is a function of operational units or even the information technology department. Therefore, it is beneficial to elucidate the differences and similarities amid continuous auditing and continuous monitoring, as many people confuse the terms. The main differences between the two terms center on purpose and responsibility of the process. The Internal Audit Department is responsible for all internal audits and audit functions, which includes testing the design and operation of internal controls. One of the expectations of an internal audit is to provide ongoing assurance and timely feedback on risk and control issues to company management. Continuous auditing is a methodology that encompasses any technique or process employed by auditors to conduct nonstop auditing (Warren \& Smith, 2006); these procedures are performed concurrently or in a brief period immediately following the event that triggered the audit (Canadian Institute of Chartered Accountants - CICA, 1999). The company's upper management is responsible for the continuous monitoring that provides oversight of the effectiveness of internal controls. Overall, upper management is liable for the implementation, enforcement, and monitoring of internal controls while the Internal Audit Department (under the Chief Internal Auditor) is responsible for examining the application and function of the internal controls. Irrespective of the differences between these two functions, each serves to regulate and monitor by analyzing real-time data compared to a predetermined 
collection of rules (Hillo \& Weigand, 2016). Alles et al. (2006) argue that continuous monitoring and continuous auditing are inseparable in financial processes.

Continuous auditing systems can be readily adapted to incorporate continuous monitoring systems. Cangemi (2010) believes that the internal audit function is well-positioned to identify potential areas for continuous monitoring, which offers many benefits. According to Deloitte Development LLC (2010), continuous monitoring is a continuous, systematic process that empowers administrators to: "(1) assess the effectiveness of controls and detect associated risk issues; (2) improve business processes and activities while adhering to ethical and compliance standards; (3) execute more timely quantitative and qualitative risk-related decisions; and (4) increase the cost-effectiveness of controls and monitoring through IT solutions." If internal auditors can rely on the continuous monitoring and reinforcement of a process by management, then testing of that specific area can be reduced and focus shifted to other areas that have not implemented constant monitoring. By integrating continuous auditing with incessant monitoring, a higher level of assurance can be achieved (Verver, 2017) and audit efficiency and effectiveness can be enhanced through the reduction of both costs and audit effort (Majdalawieh et al., 2012).

Continuous monitoring is no longer restricted to tabular reports or spreadsheets that must be analysed further. Visual reporting, when utilized as a constant monitoring technique, helps management gain immediate, valuable insights into their data through charts, maps, graphs, and dashboards. Also, with visual reporting technology, the user can gain a broad picture of the data while having the ability to immediately interact with the data and drill down into the detail when needed.

\subsection{Scenario}

The University Internal Audit Department identified one of its weaknesses to be a lack of data analytical skills, which is not uncommon in other organizations. Training audit personnel to be able to utilize analytical procedures is critical to effectively performing continuous auditing by uncovering anomalies and trends (Hoffer, 2007). Over three years, Internal Audit developed a data analytics technology strategy to overcome this weakness. Part of that strategy included the hiring of a consultant to train eight staff members; the staff were introduced to visual reporting. Over time, internal audit management determined that value could 
be added to the rest of the university community by advocating the development and implementation of continuous monitoring applications in certain business units.

Internal audit leadership knew that it would need to choose an area that resulted in a "win" in the first implementation so as not to discourage the use of continuous monitoring in other business units. When selecting a business process or operation to consider for this project, department leaders wanted a business process that would be more straightforward than some of the more complex processes, e.g., payroll or billing, and a collaborative business unit that would be receptive to this project. The University Materials Management Section, which is responsible for the procurement card program (hereafter referred to as ProCard ${ }^{\mathrm{TM}}$, sometimes referred to as P-card), was approached with the idea of having their compliance officer work with internal audit to develop a visual reporting tool to monitor the usage and compliance with ProCard ${ }^{\mathrm{TM}}$ policies.

\section{OVERVIEW OF THE PROCARD ${ }^{\text {TM }}$ PROGRAM}

The ProCard ${ }^{\mathrm{TM}}$ is a corporate Visa credit card that is for business use only. The program ${ }^{1}$ was implemented to reduce documentation volume and processing cost and to allow for a more efficient purchase of small-valued services and goods. Figure 1 represents the process flow of the university's ProCard ${ }^{\mathrm{TM}}$ program. To apply for a ProCard ${ }^{\mathrm{TM}}$, university employees must receive approval from their dean or department head, attend a training session, and sign a card use agreement before they can use the ProCard ${ }^{\mathrm{TM}}$ assigned to them. Although the ProCard ${ }^{\mathrm{TM}}$ is in the employee's name, the liability rests with the university instead of the individual cardholders. Specific vendors are selected via a bidding process.

\subsection{ProCard ${ }^{\mathrm{TM}}$ Program Risks and Controls}

Because purchases are reviewed after-the-fact and have a greater likelihood of misuse and policy abuse, the ProCard ${ }^{\mathrm{TM}}$ program is considered a high-risk area where preventative controls may have more impact than detective and corrective controls.

\footnotetext{
1 The ProCard ${ }^{\mathrm{TM}}$ program is not unique to the University as many organizations have implemented a procurement card program. Further information on procurement cards can be found at www.napcp.org.
} 


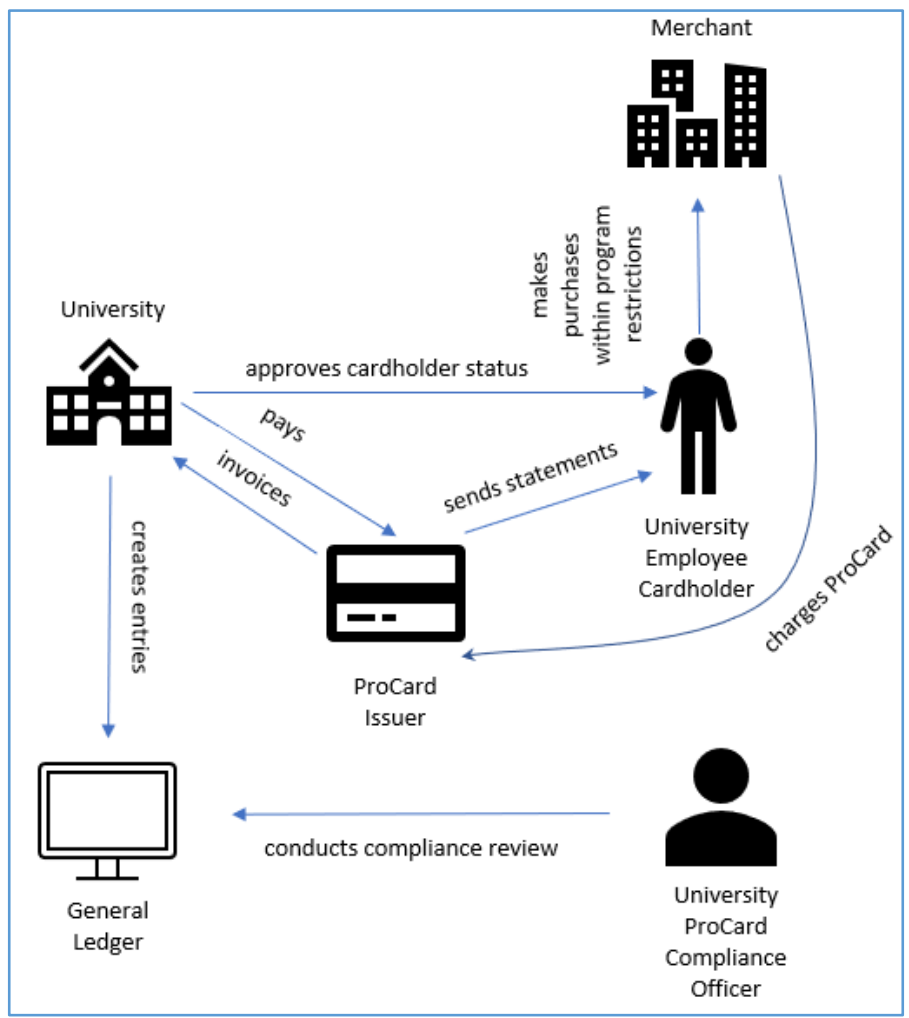

Figure 1. Process Flow of the University's ProCard ${ }^{\mathrm{TM}}$ Program - adapted from NAPCP ${ }^{2}$

To reduce the risk of misuse, an organization can implement preventive controls, e.g., conduct background checks when employees are hired and periodic postemployment background checks; maintain a clear chain of command identifying roles and responsibilities; educate employees on policies and procedures; set dollar limits on daily and monthly transactions; restrict purchases by merchant category codes (MCCs) ${ }^{3}$; prohibit multiple purchases from the same vendor within a period; and enforce compliance via a disciplinary process for noncompliance. Failure to follow the policies and procedures and repeated abuse by a cardholder should result in disciplinary actions such as revoking the ProCard ${ }^{\mathrm{TM}}$ or prosecution when fraud has occurred. Detective controls that can be employed are the reconciliation and review of documentation by someone other than the cardholder, daily and monthly assessments by the ProCard ${ }^{\mathrm{TM}}$ compliance officer, and the launch and regular check

\footnotetext{
${ }^{2}$ For more information, see "How P-Cards Work." at http://www.napcp.org/?PCardProcess.

$3 \mathrm{MCC}$ is a system of four-digit codes that is used by credit card companies to distinguish a merchant's principal trade, profession, or line of business. For example, the MCC Code 4900 represents utilities. http://mcc-codes.findthecompany.com/.
} 
of an anonymous tip line. Incorporating such preventive and detective controls allows for a strong continuous monitoring system to serve as an effective fraud deterrent, especially since it allows for early notification of potential fraudulent activity (Gonzalez \& Hoffman, 2018). Even with these internal controls in place, there is the risk of cardholders using the ProCard ${ }^{\mathrm{TM}}$ for personal gain such as gas for a personal car, household items, utilities, and gift cards. For instance, former West Virginia Supreme Court Justice Loughry was found guilty of personal use of state fuel cards (Klein, 2019). Therefore, the use of data analytics to provide insight into the types and number of purchases by cardholders and departments, as well as monitoring for questionable purchases, is paramount.

\subsection{ProCard ${ }^{\mathrm{TM}}$ Program Restrictions}

For internal control purposes, restrictions were implemented by the university. One of the controls is limiting the dollar amount an employee can spend on a single transaction, daily transactions, and monthly transactions, which reduces the risk of total dollars that can be spent. Spending limits (or levels) are determined by the employees' supervisor. Table 1 shows the categories of the university's spending levels. If a special situation arises and the spending level is too low, materials management is contacted to ascertain whether to allow the transaction to be processed.

\begin{tabular}{|l|r|r|r|}
\hline \multicolumn{4}{|c|}{ Spending Levels } \\
\hline & Single Limit & Daily Limit & Monthly Limit \\
\hline Level 3 & $\$ 1,500$ & $\$ 3,000$ & $\$ 10,000$ \\
\hline Level 4 & $\$ 2,500$ & $\$ 5,000$ & $\$ 15,000$ \\
\hline Level 5 & $\$ 5,000$ & $\$ 10,000$ & $\$ 25,000$ \\
\hline Level 6 (port only) & $\$ 1,500$ & $\$ 3,000$ & $\$ 10,000$ \\
\hline Level 7 (port only) & $\$ 5,000$ & $\$ 10,000$ & $\$ 25,000$ \\
\hline
\end{tabular}

Table 1. ProCard ${ }^{\mathrm{TM}}$ Spending Levels for Cardholders. Source: Authors

Another restriction stipulates that employees are not allowed to split ${ }^{4}$ transactions to circumvent the spending limit policy. However, some purchases are not considered split transactions, such as registering multiple employees for the same conference or buying multiple airline tickets.

\footnotetext{
${ }^{4}$ For example, an employee has a limit per transaction of $\$ 500$; the total purchase of items from a vendor on the same day is $\$ 600$; the purchase is split into two transactions for $\$ 300$ each to stay under the spending limit.
} 
The university, to the extent possible, has restricted certain merchant category codes (MCCs) such as alcohol beverage stores, pawnshops, and gaming establishments. Nonetheless, with some vendors selling multiple products, it is often difficult to block certain purchases. Different levels of transaction data (hereafter referred to as data levels) can be captured and transmitted to the university; however, not all vendors elect to capture and provide the level of detail that is needed. The loss of data is due to the type of point-of-sale system or technology utilized by the vendor; it also determines what data is captured and ultimately transmitted. In some instances, detailed hard-copy receipts must be reviewed to see line-item detail such as product code/item number, quantity, description, etc. In order to provide additional documentation clarifying the transaction, cardholders are required to enter information on purchases ${ }^{5}$ in a comment field to explain the business purpose and purchase details.

Each one of these controls represents a risk that needs to be monitored to detect a violation. Prior to the implementation of the continuous monitoring application, the ProCard ${ }^{\mathrm{TM}}$ compliance officer had to review tabular reports produced from the Works ${ }^{\circledR}{ }^{6}$ application, which was time-consuming and inefficient for some reviews.

\section{DEVELOPMENT OF THE CONTINUOUS MONITORING TOOL}

The approach used to develop the visual reporting tool to be utilized by the ProCard ${ }^{\mathrm{TM}}$ office for continuous monitoring and data insight consisted of the four phases shown in Table 2, and includes the amount of time spent on each phase by internal audit. In total, internal audit spent approximately 332 hours on the project.

\subsection{Planning Phase}

During the planning phase, the internal audit project leader gathered background information on procurement card programs in general and researched information available on utilizing data analytics for reviewing ProCard ${ }^{\mathrm{TM}}$ transactions.

\footnotetext{
${ }^{5}$ For example, if purchasing gift cards from Wal-Mart to give to participants involved in a research study, the cardholder would enter the name of the research study.

${ }^{6}$ Works ${ }^{\circledR}$ is a Web-based electronic card payment management application that allows for the management of purchasing card transactions.
} 


\begin{tabular}{|c|c|}
\hline Phase & Percentage of Time Spent \\
\hline I. Planning & $35 \%$ \\
\hline II. Obtaining and Understanding the ProCard ${ }^{\mathrm{TM}}$ Data & $10 \%$ \\
\hline III. Developing the Continuous Monitoring Application & $50 \%$ \\
\hline IV. Turning the Project Over to the User & $5 \%$ \\
\hline
\end{tabular}

Table 1. Development Phases and Percentage of Time Spent by Internal Audit

Research shows there is a strong influence of management support and advocacy on successfully implementing applications that support continuous monitoring and continuous auditing (Adesina et al., 2016; Mainardi, 2011; Soedarsono et al., 2019; Vasarhelyi et al., 2012). Hence, an initial meeting was held with materials management personnel to secure collaboration on the project. The project leader explained the purpose of the project, and a subject matter expert (SME) was identified, which was the ProCard ${ }^{\mathrm{TM}}$ program compliance officer. During this meeting, the project leader obtained preliminary information such as the number of cardholders, what types of reviews were currently being performed, and the process used to complete the analyses to best determine the data needed.

A subsequent meeting was held by the project leader to brainstorm on potential tests that could be conducted and to identify questions or items that still needed to be addressed. This meeting included the SME, a consultant ${ }^{7}$, management members familiar with the continuous monitoring system's capabilities, and some of the internal audit staff. During the brainstorming session, the project leader reminded group members to not limit their suggestions because they assumed the data was unavailable, the test could not be performed, or the question could not be addressed.

\subsection{Obtaining and Understanding the ProCard ${ }^{\mathrm{TM}}$ Data Phase}

ProCard ${ }^{\mathrm{TM}}$ transactions are managed through Works ${ }^{\circledR}$, which is an online software solution provided by the bank utilized. The ProCard ${ }^{\mathrm{TM}}$ administrator gave the project leader access to the Works ${ }^{\circledR}$ system by setting up a login account. The project leader downloaded the data needed into an Excel spreadsheet and worked with the consultant and SME to further understand the data. The review suggested

\footnotetext{
${ }^{7}$ Internal Audit obtained the services of Visual Risk IQ as part of its data analytics strategy. More on Visual Risk IQ will be discussed later in the paper.
} 
that some data attributes needed to be standardized, such as vendors' names.

When merging the use of data between two or more departments or areas, certain items should be standardized such as vendors' names, account numbers, and addresses. In some instances, a vendor may be in the system under several different names. Rather than having a balance presented for each version of a vendor's name, all transactions through that specific vender should be combined and presented under one balance. For example, the vendor name for Wal-Mart may sometimes be Wal-Mart or Wal-Mart Superstore. Hence, all transactions that were made through any version of the Wal-Mart name were combined to be presented as one balance for Wal-Mart. A similar process was used for vendors' account numbers and addresses.

These deliberations also uncovered different data levels that could be captured and transmitted depending on the point-of-sale system and technology utilized by the vendor. Table 3 depicts the data levels.

\begin{tabular}{|c|c|c|c|c|c|c|}
\hline & Date & Supplier & $\begin{array}{c}\text { Transaction } \\
\text { Amount }\end{array}$ & Sales Tax & $\begin{array}{c}\text { Customer-Defined } \\
\text { Code } \\
\end{array}$ & $\begin{array}{c}\text { Line-Item } \\
\text { Detail }\end{array}$ \\
\hline Level I Standard & $V$ & $V$ & $V$ & & & \\
\hline Level II Variable Data & $\checkmark$ & $V$ & $\checkmark$ & $V$ & $V$ & \\
\hline Level III Detailed Data & $V$ & $V$ & $V$ & $V$ & $V$ & $V$ \\
\hline
\end{tabular}

Table 2. Levels of Transaction Data for ProCards ${ }^{\mathrm{TM}}$ Source: NAPCP

It should be noted that the quality and completeness of line-item detail data can vary depending on the vendor. For instance, a transaction that has "Level III Detailed Data" might have many line-items depending on what was purchased. Not all data has the Level III detail, but for the transactions that do, the data needs to be parsed or separated by each line-item.

The consultant utilized the structured query language (SQL) to standardize the data for vendors' names and deconstruct the transactions into Level III detail. However, the project leader needed a way to sustain this project without having to rely on the consultant. A meeting was held with the university's information technology group. It was determined that a database would be set up on a SQL server, and scripts were to be run to standardize and parse the data before it was loaded into the continuous monitoring application.

Many have heard the saying, "garbage in, garbage out" (Search Software Quality,

\footnotetext{
8 "Levels of Transaction Data". For more information, see http://www.napcp.org/?page=LevelsofData.
} 
2008). Results of continuous monitoring and continuous auditing are dependent upon the quality of the available data (Chan \& Vasarhelyi, 2018; Kuhn \& Sutton, 2010; Soedarsono et al., 2019). Hence, the data must be accurate and complete. Control balances were obtained from the SME and compared to the extracted data to confirm it was correct. Once the data was obtained, standardized, and evaluated for completeness and accuracy, the project leader developed the continuous monitoring application.

\subsection{Developing the Continuous Monitoring Application Phase}

The project leader utilized Tableau', a software tool, to build a continuous monitoring application for ProCard ${ }^{\mathrm{TM}}$ transactions in the form of a storyboard ${ }^{10}$. The application was designed to allow a user to (1) select an item from a list of questions that best describes the desired action and (2) to monitor the data for policy abuse and personal purchases. Figure 2 shows part of the storyboard built for this application.

The storyboard offers users a variety of items, in a question format, for selection (Refer to Table 4 for the list of questions). First, a user selects the question to which they want a response and the system displays a visual for further review. The application is interactive allowing the user to review different data levels and apply data filters, including searching for keywords such as "gifts." Examples of the continuous monitoring application are presented as screenshots in Appendices 1 through 13. Cardholders' names are redacted from the screenshots to maintain personal privacy.

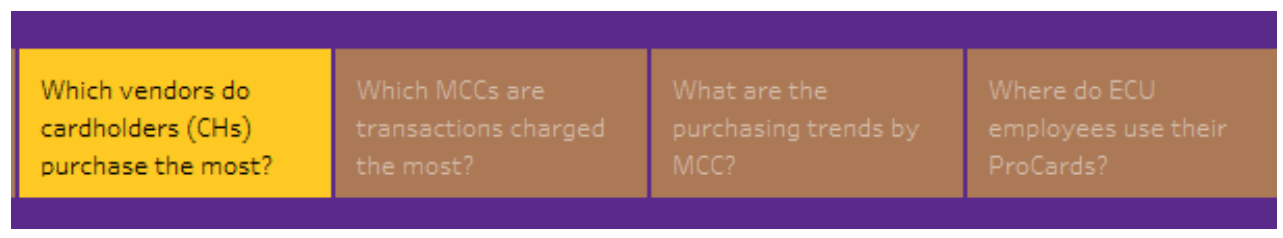

Figure 2. Storyboard for ProCard ${ }^{\mathrm{TM}}$ Continuous Monitoring Application

\footnotetext{
9 Tableau is a business intelligence software that allows a user to explore and perform valuable analysis of data. Further detail of why this software was selected is discussed in the last section of the paper.

${ }^{10}$ In Tableau, a storyboard is a sequence of visualizations that is used to together to tell a story about the data and provide context where needed.
} 


\begin{tabular}{|c|c|}
\hline No. & Questions \\
\hline 1 & Which vendors do cardholders $(\mathrm{CHs})$ purchase the most? \\
\hline 2 & Which MCCs are transactions charged the most? \\
\hline 3 & What are the purchasing trends by MCC? \\
\hline 4 & Where do employees use their ProCards? \\
\hline 5 & What are the purchasing trends by vendor zip? \\
\hline 6 & What are the purchasing trends by cardholders by total amount? \\
\hline 7 & What are the purchasing trends by cardholders by number of swipes? \\
\hline 8 & What purchases are the cardholders making? \\
\hline 9 & Are cardholders using preferred vendors? \\
\hline 10 & Do the transactions follow Benford's Law? \\
\hline 11 & Do transactions by MCC follow Benford's Law? \\
\hline 12 & Are cardholders with a $\$ 1,500$ transaction limit splitting transactions? \\
\hline 13 & Are cardholders with a $\$ 2,500$ transaction limit splitting transactions? \\
\hline 14 & Are cardholders with a $\$ 5,000$ transaction limit splitting transactions? \\
\hline 15 & Are departments splitting transactions among multiple cardholders? \\
\hline 16 & How are purchases divided amongst the days of the week? \\
\hline 17 & Which cardholders are making purchases on the weekends? \\
\hline 18 & Have transactions posted to blocked MCCs? \\
\hline 19 & Have transactions posted to questionable MCCs? \\
\hline
\end{tabular}




\begin{tabular}{|l|l|}
\hline 20 & Are any vendors used by only one department? One only one cardholder? \\
\hline 21 & Do cardholders have a low number of transactions with high dollar amounts? \\
\hline 22 & Are there round dollar transactions? \\
\hline 23 & Are cardholders making purchases at local vendors? \\
\hline 24 & What transactions have posted using top key words? \\
\hline 25 & Have questionable items been purchased? \\
\hline
\end{tabular}

Table 3. Questions Answered Through the Storyboard

The continuous monitoring application was designed to provide management with valuable insights into the data that was not readily available in the old system. Appendices 1 through 5 provide screenshots of the ways in which management can now view purchasing trends to make better business decisions, such as pursuing better prices on certain goods and services. Appendices 6 through 13 present screenshots of processes management can use in the application to monitor compliance with the ProCard ${ }^{\mathrm{TM}}$ policies. For example, cardholders should not split transactions to avoid spending limits. Appendix 6 shows a screenshot of the process used when the user monitors for split transactions by cardholders with a spending limit of $\$ 1,500$. Prior to the implementation of the continuous auditing-monitoring tool, the user reviewed multiple tabular reports to assess ProCard ${ }^{\mathrm{TM}}$ transactions for split transactions. Now, the user immediately sees possible split transactions and can sort through the data for further details. This process not only results in a reduction of the time (and cost) it takes to monitor for split transactions but immediately identifies potential cardholder abusers ${ }^{11}$.

Another area that needs to be monitored for compliance is ensuring cardholders are using preferred vendors for certain purchases. The University is a state entity and must utilize certain vendors for specific types of goods and services that are purchased because the vendors are on state contract. Before the implementation, the user had to manipulate numerous reports in Excel to determine if certain goods and services were purchased on state contract. In the current system, the user can

\footnotetext{
11 Potential future fraudsters periodically test systems and their boundaries for weaknesses and enforcement of compliance sometimes for years before actually perpetrating a fraud (Albrecht et al., 2016).
} 
employ the continuous monitoring application and instantly see if cardholders are using preferred vendors. Appendix 7 contains a screenshot of how the user can monitor for compliance with cardholders using preferred vendors. Additionally, the user can choose from a drop-down menu of the types of goods and services that are on State contract.

Because ProCards are considered high-risk, management should also monitor for personal purchases. Appendices 8 through 13 provide screenshots of the application in action when monitoring for personal purchases. Previously, the user would have to manipulate and review multiple tabular reports to evaluate purchase data for suspicious transactions. Also, internal auditors would have to request hard copies of ProCard ${ }^{\mathrm{TM}}$ statements and receipts and manually review them for suspicious transactions. With the current system, auditors can utilize the continuous monitoring application to review for suspicious transactions; the application also helps with the investigation of allegations received involving misuse of university resources. Another benefit of this continuous monitoring application is that the internal audit leadership can employ it to assess for acquiescence with the Fair Labor Standards Act, which mandates that non-exempt employees be paid or receive comp-time of one and half hours for time worked over forty hours in one week. By reviewing purchases made on weekends, internal auditors can compare this to the timekeeping system to determine if non-exempt employees have correctly recorded their work time.

Financial services also utilizes the continuous monitoring application to identify cardholders who have purchased gift cards to ensure the cardholders have registered with materials management to buy gift cards. In the old system, financial services would have to manually review ProCard ${ }^{\mathrm{TM}}$ statements and receipts. In the new setup, they utilize the continuous monitoring application to perform a search for the word "gift" to identify potential gift card purchases.

\subsection{Turning the Application Over to the User}

Once the project leaders and SME were confident the data was acceptable and the tool was meeting the needs of the end user, the application was turned over to the user. However, internal audit's role did not stop once the tool was fully implemented. The project leader developed a list of roles and responsibilities and obtained agreement among all parties involved. See Appendix 14 for the specific roles and responsibilities of internal audit, materials management, and information 
technology regarding the continuous monitoring application. Internal audit spends approximately one to two hours a month maintaining the continuous monitoring application for materials management.

\section{OVERCOMING THE CHALLENGES}

As with any project, there are going to be challenges that need to be addressed. The most common challenges include management cooperation, affordability and usability of data analytical tools, obtaining and understanding data, and sustaining the continuous monitoring application.

\subsection{Management Cooperation}

One common challenge is finding a user who is interested and supportive of the project. In this instance, the user was willing to collaborate on a continuous monitoring project but did have some reservations or apprehension about how this application would replace the tabular report review. Internal audit leadership suggested that the tool not replace the tabular reports but rather complement them until the end user was more comfortable with the continuous monitoring application. To ensure a successful system development and implementation, the project's end user must be included in the project, from beginning to end, and continuously share the feedback and output. Additionally, inclusion gives the user ownership and some control over the project increasing the likelihood of project success.

While the project is being planned and developed, the final user should be trained on navigating and effectively using the new tool. Initially, the user felt overloaded with information and overwhelmed by the entire storyboard. To ease the transition, the project leader suggested that the user start by selecting one of the questions in the storyboard. The user chose the split transaction question, "Are cardholders with a \$1500 transaction limit splitting transactions?" and compared the application's results to the tabular report that was previously utilized to check for compliance. When using tabular reports from Works ${ }^{\circledR}$, the user had to review multiple reports to complete the task: one report was evaluated for potential split transactions and another report was reviewed for transaction details. By using the storyboard in the continuous monitoring tool, the user had immediate access to the split-transaction data and could select options to see further details. Instantly, the user realized the continuous monitoring tool was much more efficient than reviewing many tabular 
reports. See Appendix 15 for comments provided by the user regarding the continuous monitoring tool.

\subsection{Affordability and Usability of Data Analytical Tools}

The affordability and usability of data analytical tools can be crushing to small internal audit units. They may not have the budget to buy the necessary tools or capable personnel to operate the tools. Some internal audit functions do not know where to start. So, rather than jumping into a project, it is helpful to plot out a data analytics and technology strategy and get cooperation from senior administrators who control the budget. Internal audit is deemed a trusted advisor in the university and has the support of senior management, so the initial funding for this project was not an issue. Also, internal audit took the opportunity to demonstrate to senior management and the board of trustees the success stories of utilizing data analytics in the department, which was key to obtaining further funding for a data analytics program.

Rather than have one subject matter expert in the internal audit function, it was decided that the entire audit staff be required to use data analytical tools. Since the audit staff was comfortable using Excel, the ActiveData ${ }^{12}$ plug-in was purchased for all staff members and in-house Excel training for data analytics was provided through AuditNet ${ }^{13}$ webinars. From there, the internal audit department partnered with Visual Risk IQ ${ }^{14}$ to provide training and support for its data analytics program. Visual Risk IQ introduced its QuickstartTM methodology, which was adopted by the internal audit department for its projects. The five phases of this methodology are: (1) brainstorm, (2) acquire and map data, (3) write queries, (4) analyze and report, and (5) refine and sustain. Instead of relying on the traditional approach to building an audit program for assurance and consulting engagements, the internal audit department now starts with brainstorming and asks, "What question(s) do we want to answer?" After responses to these questions are developed, a determination is made as to the data level that is needed, whether it can be obtained, and the

\footnotetext{
12 ActiveData for Excel is a plug-in for Microsoft Excel that has advanced data analytical tools. http://www.informationactive.com

${ }^{13}$ AuditNet is a subscription based service that provides resources for auditors. www.auditnet.org

${ }^{14}$ Visual Risk IQ is a services and software firm that helps people see and understand their data. They primarily serve internal audit and compliance professionals, and provide data analytics consulting, implementation, and education. www.visualriskiq.com For more information about the Quickstart ${ }^{\mathrm{TM}}$ methodology, visit http://www.visualriskiq.com/vriqfor-internal-audit/.
} 
location of the data supply. Then, queries are written to answer the questions, and the results are analyzed and reported.

While working with Visual Risk IQ, they introduced internal audit to the concept of visual reporting and, specifically, to the visual reporting tool Tableau. After working with Visual Risk IQ on several projects, internal audit management determined that visual reporting could be utilized for continuous monitoring for some of the business operations.

\subsection{Obtaining and Understanding the Data}

Obtaining and understanding the data is probably the most frustrating part of utilizing data analytics. There are times when the internal auditors identify what is wanted and how to do it, only to find the data is unavailable or the ERP system cannot be comprehended without an SME. Also, data owners are sometimes reluctant to release the data due to security concerns. Unless the internal audit department has the user and the SME's buy-in on the project, it is doubtful the project will be successful.

Internal audit can sometimes retrieve the data from data warehouses; however, often they must rely on SMEs to obtain data that is not stored in a data warehouse. It is not unusual to run into scheduling conflicts and have to work around the SME's schedule. Sometimes, data dictionaries are non-existent or lacking in explaining the fields. For this project, the data was straightforward and easily obtainable; however, this has not been the case in other projects. Internal auditors must have tenacity, perseverance, and not give up when trying to obtain the data but also be flexible and work with other employee's schedules.

\subsection{Sustaining the Application}

After a continuous monitoring application is implemented, it must be sustained. To maintain an application, generally, personnel from different areas have to be involved. For this continuous monitoring application, personnel from the internal audit, materials management, and information technology departments agreed to specific roles and responsibilities (see Appendix 14 for a list of specific roles and responsibilities). Internal audit also should contact users at least once a month to learn if any modifications are needed and to ensure the business unit is still using the application. 


\subsection{Concluding Comments and Future Initiatives}

Overall, this was a very successful project. Further, it demonstrates the role that internal audit can play regarding continuous monitoring. Nonetheless, to be successful, internal audit must be seen as a trusted advisor since implementing a continuous monitoring tool is not just about the technology but is also about securing commitment, reinventing processes, and changing organizational behavior. By integrating continuous auditing and continuous monitoring, a more robust process for compliance monitoring can be established for high-risk business processes.

In this case, the continuous monitoring application reduced the time required to review ProCard ${ }^{\mathrm{TM}}$ transactions for compliance with policies and improved risk and control assurance. Besides being an effective tool for materials management, the application helped internal audit decrease the time involved to conduct a fraud and abuse investigation when an allegation is received about the personal use of a ProCard ${ }^{\mathrm{TM}}$. Moreover, internal audit management uses the tool to ensure compliance with the Fair Labors Standards Act (FLSA) by reviewing weekend purchases and reminding management that if non-exempt employees purchase goods on the weekend, the employees must be paid for their time. Financial services found the continuing monitoring application to be effective in monitoring for compliance with gift card policies. Other business units have recognized the success of this project's implementation across the university and the internal audit department is now working on continuous monitoring applications for accounts payable and dental medicine revenues.

\section{ADDITIONAL EXAMPLES AND FUTURE RESEARCH TOPICS}

Other areas ripe for continuous monitoring that are also considered at-risk areas include asset management and payroll. Typically, these two areas are the greatest areas of cost for an organization and can quickly become problematic if not adequately observed.

Implementation of continuous monitoring of assets, combined with continuous auditing, may improve not only the cost of maintaining assets but an entity's asset management bottom line. For instance, if a specific brand or model of work laptop has a high percentage of problems and early replacement, this information will assist management in identifying areas where another laptop brand or model may 
be better suited, improve employee efficiency, and lower costs related to the increase in replacements. Poor monitoring can result in the loss of thousands of dollars or more. For a number of years, the State of West Virginia's Fleet Office insured around 12,000 vehicles, but after a three-year investigation, discovered that the state only owns 8,380 vehicles (Reyes, 2019). Continuous monitoring would have detected the problem and prevented future issues if it had been applied.

Continuous monitoring in the functional area of payroll will assist managers in quickly identifying employees who may have over- or under-reported work hours and unauthorized overtime. These dimensions of payroll often require auditing follow-up and thus could benefit from continuous monitoring. In one recent case, Furry v. East Bay Publishing (2018) cited the failure of an employer to maintain accurate employee work-hour documentation. A California appeals court ruled in favour of the former employee that imprecise evidence provided by an employee provided a sufficient basis for determining damages, and awarded the plaintiff with the contested overtime pay.

In a case that demonstrates the power of good policies, procedures, and time documentation, Jong v. Kaiser Foundation Health Plan (2014), a California appeals court ruled in favour of Kaiser. The court refused to hold the company liable since Jong did not provide evidence that Kaiser knew he completed overtime hours, a necessary legal requirement to prove "working off the clock." Such court findings signify the importance of maintaining accurate time records as required by state and federal law. Furthermore, COVID-19 has caused upheaval of work patterns and recent changes in laws, i.e., the Coronavirus Aid, Relief, and Economic Security (CARES) Act (2020), has cast the need for internal controls over an already inherently high-risk process into the forefront. Currently, little is known about the impact of the pandemic, but it will be studied and impact research for many years to come.

There are two additional areas of continuous monitoring where more research is needed. First, the use of continuous monitoring is only going to increase as the business environment evolves in response to the mass retirements of the baby boomer generation and the increase in technology use such as that caused by the recent pandemic. Additional research is needed to examine the use of continuous monitoring applied to the adoption of the Europay, Mastercard, and Visa (EMV) chip; as usage increases and the capability of EMV chips evolve, organizations will 
have access to more data and further control over ProCard ${ }^{\mathrm{TM}}$ purchases by implementing restrictions through the smart chip. Second, as the use of continuous monitoring and asset management increases, future research should examine the role of continuous monitoring in decreasing asset and related maintenance cost.

\section{EDUCATOR USE OF THE ARTICLE}

To encourage further use or discussion of this case in a course, instructors can utilize one of the following options:

1) Ask students to identify other areas within the business environment, and related to a specific course topic, that may benefit from the application of continuous monitoring. Additional discussion may include the process for the implementation.

2) Ask students to identify events in the news, which are similar to those provided in this article, and to identify internal control weaknesses that may be mitigated through continuous monitoring.

3) Prior to introducing students to Tableau, SQL, or similar programs, instructors can ask students to read the article and to identify information that should be incorporated into the specific program during the development phase.

4) First, ask students to identify preventative and detective controls in the paper. Second, ask students to research for news articles and legal cases in which internal controls were an issue. Finally, have students develop preventative and detective controls that could have been implemented to have corrected the internal control weakness.

These options are to assist instructors in using the article and free online resources towards developing students' applicable knowledge on internal controls and continuous monitoring. 


\section{REFERENCES}

Adesina, O. T., Olugbenga, O. M., \& Zaccheaus, S. A. (2016). Achievement of assurance, continuous and risk assessment through continuous auditing for effective and efficient management. European Journal of Business, Economics and Accountancy, 4(1), 55-67. http://www.idpublications.org/wp-content/uploads/ 2015/12/Full-Paper-ACHIEVEMENT-OF-ASSURANCE-MONITORING-ANDRISK-ASSESSMENT.pdf Accessed 7 October 2020

Albrecht, W. S., Albrecht, C. O., Albrecht, C. C., \& Zimbelman, M. F. (2016). Fraud examination (5th ed.). Boston, MA: Cengage Learning.

Alles, G. M., Tostes, F., Vasarhelyi, A. M., \& Riccio, L. (2006). Continuous auditing the USA experience and considerations for its implementation in Brazil. Journal of Information Systems and Technology Management, 3(2), 211-224. https://search.proquest.com/docview/233645483/7F67173D7C99430DPQ/7?acco untid=10639 Accessed 7 October 2020

Canadian Institute of Chartered Accountants (CICA). (1999). Continuous Auditing: Research Report.

Cangemi, A. (2010). Internal audit's role in continuous monitoring. EDPACS: The EDP Audit, Control, and Security Newsletter, 41(4), 1. https://doi.org/https://doi.org/https://doi.org/10.1080/07366981.2010.488571

Chan, D. Y., \& Vasarhelyi, M. A. (2018). Innovation and practice of continuous auditing. International Journal of Accounting Information Systems, 12(2), 152160. https://doi.org/https://doi.org/https://doi.org/10.1016/j.accinf.2011.01.001

Deloitte Development LLC. (2010). Continuous monitoring and continuous auditing: from idea to implementation. https:/www2.deloitte.com/content/dam/ Deloitte/us/Documents/audit/us-aers-continuous-monitoring-and-continuousauditing-whitepaper-102910.pdf Accessed 7 October 2020

Furry v. East Bay Publishing, LLC. (2018) 30 Cal. App. $5^{\text {th }} 1072$.

Gonzalez, G. C., \& Hoffman, V. B. (2018). Continuous auditing's effectiveness as a fraud deterrent. Auditing: A Journal of Practice and Theory, 37(2), 225-247. https://doi.org/https://doi.org/10.2308/ajpt-51828

Hillo, R., \& Weigand, H. (2016). Continuous auditing and continuous monitoring: Continuous value? IEEE Tenth International Conference on Research Challenges in Information Science (RCIS), 1-11. https://doi.org/https://doi.org/10.1109/ RCIS.2016.7549279 
Hoffer, R. M. (2007). The value of continuous auditing. EDPACS: The EDP Audit, Control and Security Newsletter, 35(6), 1. https://doi.org/https://doi.org/ $10.1080 / 07366980701475812$

Jong v. Kaiser Foundation Health Plan, Inc. (2014) 226 Cal. App. $4^{\text {th }} 437$.

Klein, D. (2019). Former W.Va. Supreme Court justice Loughry Reports to Prison. https://abcnews.go.com/US/wireStory/wva-supreme-court-justice-reports-prison62208607 Accessed 7 October 2020

Kuhn, J., \& Sutton, S. (2010). Continuous auditing in ERP system environments: the current state and future directions. The Journal of Information Systems, 24(1), 91-112. https://doi.org/https://doi.org/10.2308/jis.2010.24.1.91

Mainardi, R. L. (2011). Harnessing the power of continuous auditing: Developing and implementing a practical methodology. https://doi.org/https://doi.org/10.1002/ 9781118269121

Majdalawieh, M., Sahraoui, S., \& Barkhi, R. (2012). Intra/interprocess continuous auditing (IIPCA), integrating CA within an enterprise system environment. Business Process Management Journal, 18(2), 304-327. https://doi.org/https:// doi.org/10.1108/14637151211225216

Public Law 116-136: H. R. 748, Coronavirus Aid, Relief, and Economic Security (CARES) Act of 2020. (Date: 03/27/2020). Text from: United States Public Laws. Available from: LexisNexis ${ }^{\circledR}$ Congressional. https://www.congress.gov/bill/ 116th-congress/house-bill/748 Accessed 7 October 2020.

Reyes, R. (2019). Three years later, W. Va. uncovers its fleet count. Government Fleet, Feb. 6. https://www.government-fleet.com/324586/three-years-later-w-vafinds-a-fleet-count Accessed 7 October 2020

Soedarsono, S., Mulyani, S., Tugiman, H., \& Suhardi, D. (2019). Information quality and management support as key factors in the applications of continuous auditing and continuous monitoring: An empirical study in the government sector of Indonesia. Contemporary Economics, 13(3), 335-350. https://doi.org/https:// doi.org/DOI:10.5709/ce.1897-9254.317

Vasarhelyi, M., Alles, M., Kuenkaikaew, S., \& Littley, J. (2012). The acceptance and adoption of continuous auditing by internal auditors: a microanalysis. International Journal of Accounting Information Systems, 13(3), 267-281. https://doi.org/https://doi.org/10.1016/j.accinf.2012.06.011 
Verver, J. (2017). Continuous monitoring and auditing: what is the difference? http://pdsqa.protiviti.com/mobile/Documents/Featured-Articles/Continuous_Moni toring_Auditing.pdf Accessed 7 October 2020

Warren, J. D., \& Smith, L. M. (2006). Continuous auditing: An effective tool for internal auditors. Internal Auditing, 21(2), 27-35. https://search.proquest.com/ docview/214394157/4965B418FC664A57PQ/1?accountid=10639 Accessed 7 October 2020 


\section{Appendix 1. What are the purchasing trends by MCC?}

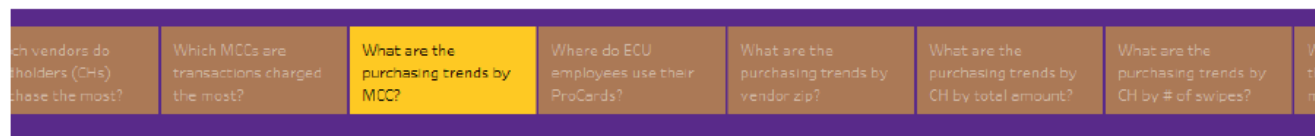

Purchases by MCC for the Statement Period in Review click the purple bar to view the MCC trend data below.

\begin{tabular}{lc} 
MCC Description & MCC \\
\hline HILTON & 3504 \\
\hline LAB/MEDICAL/DENTAL/O & 5047 \\
\hline CHARITABLE AND SOCIAL & 8398 \\
\hline BUSINESS SERVICES NOT & 7399 \\
\hline ADVERTISING SERVICES & 7311 \\
\hline MISCELLANEOUS AND RE. & 5999 \\
\hline FAST FOOD RESTAURANTS & 5814 \\
\hline AMERICAN AIRLINES & 3001 \\
\hline BOOKSTORES & 5942 \\
\hline
\end{tabular}

MCC

MCC Description

(1)

Measure Names

Amount

Number of Records

Trend Data for 12-Month Rolling Year

MCCD.. MCC Month of Post Date

LAB/ME 5047

DICAL/D

ENTA
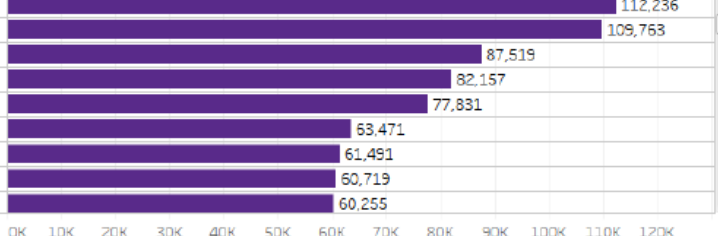

OK IDK 20K 30K 40K 50K 60K $70 \mathrm{~K}$ 80K $90 \mathrm{~K}$ 100K 110K $120 \mathrm{~K}$

Arnount $\overline{2}$
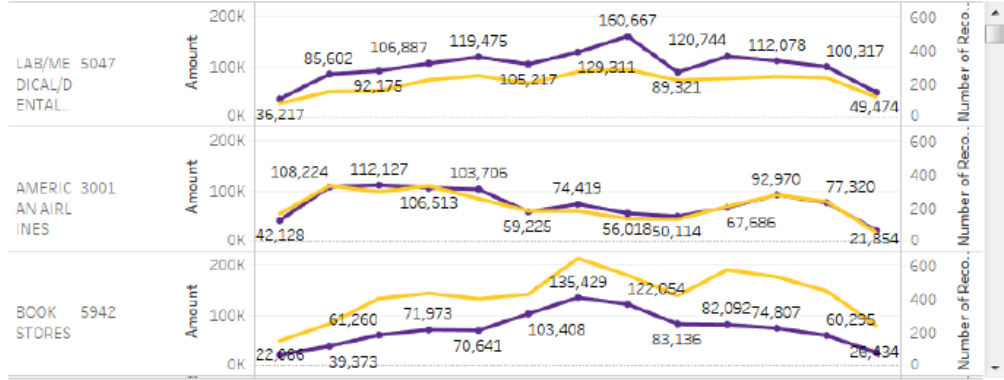$$
\mathrm{OK}
$$ 


\section{Appendix 2. Which vendors do cardholders purchase from the most?}

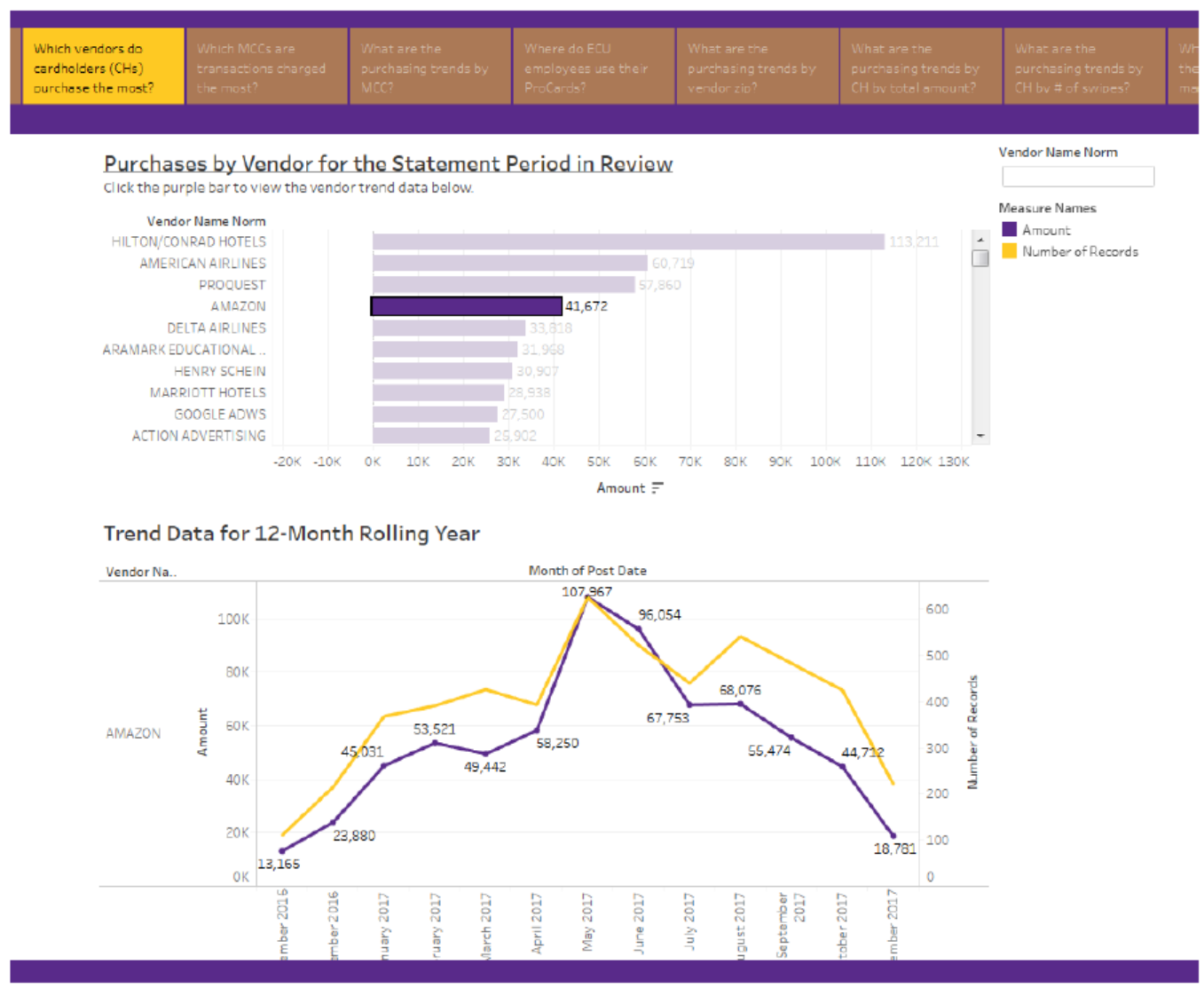




\section{Appendix 3. Where do employees use their ProCards?}

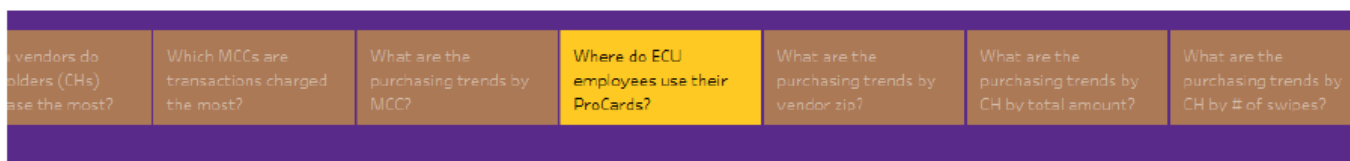

Purchases by Vendor Zip

Click the purple dots to view the vendor zip detail below.

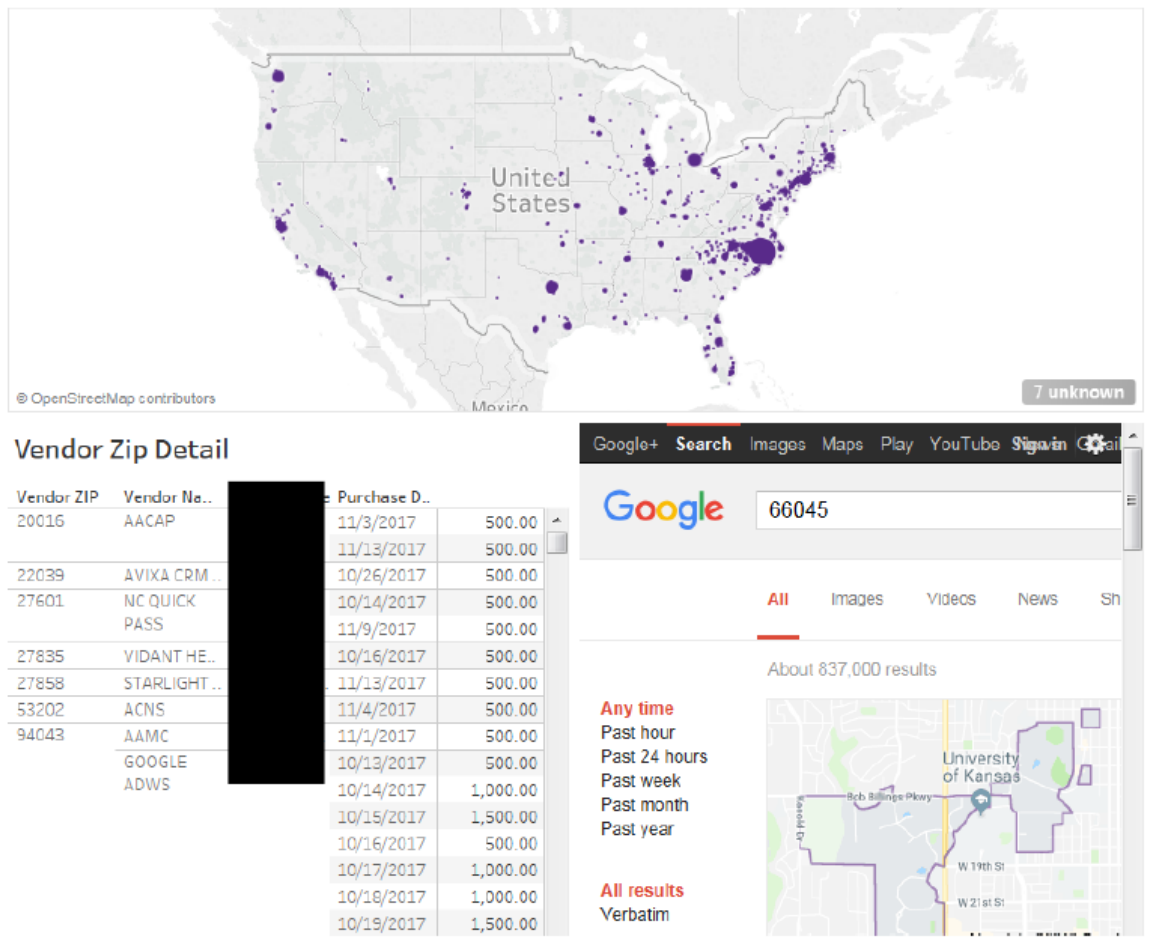

100,000

150,000 


\section{Appendix 4. What are the purchasing trends by cardholder by amount?}

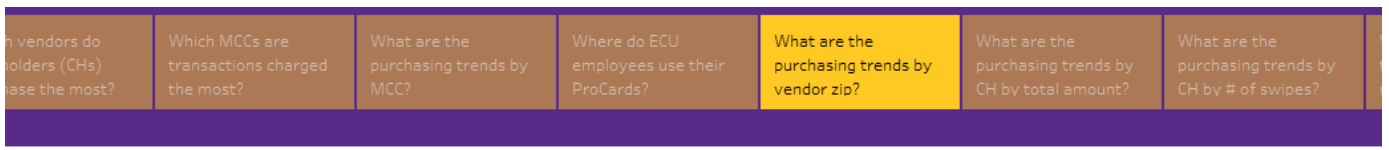

Purchases by Vendor Zip for the Statement Period in Review

Click the purple bar to view the vendor zip trend data below.

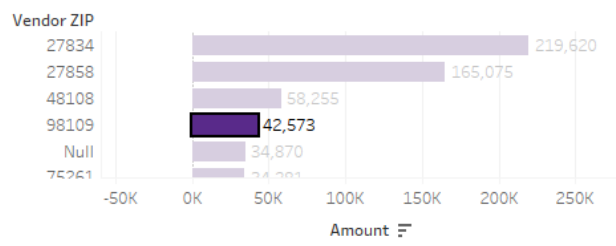

Google+ Search Images Maps PSign Hou Ho

Google 98109

Trend Data for 12-Month Rolling Year

Vendor ZIP Month of Post Date

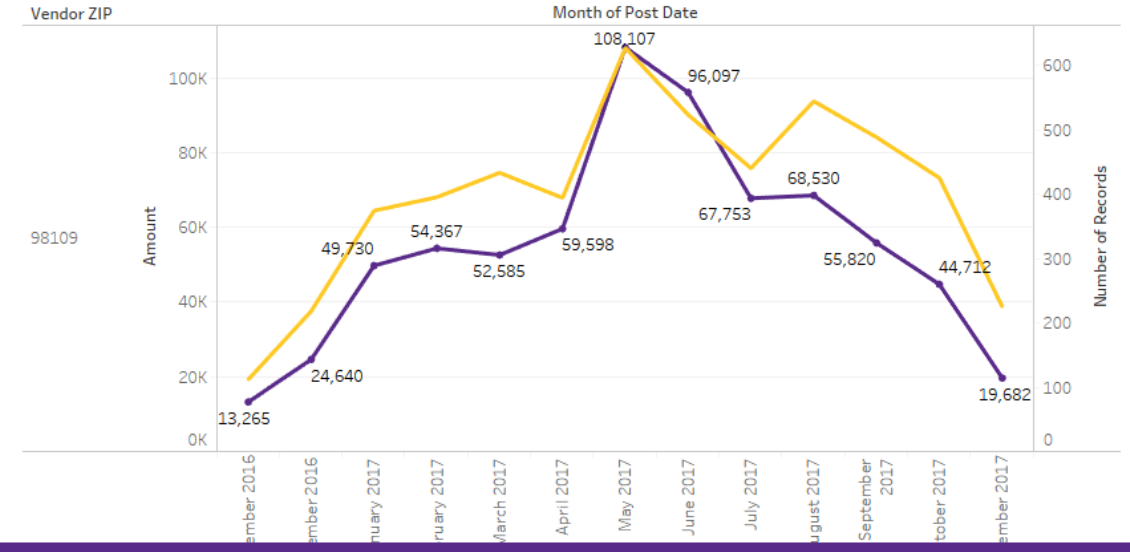

All Images Videos

About $2,750,000$ results

98109. WA Real Estate ? https://www.redfin.com/zip Instantly search and view phot estate listings updated every 1 .
Vendor ZIP 


\section{Appendix 5. What purchases are the cardholder's making?}

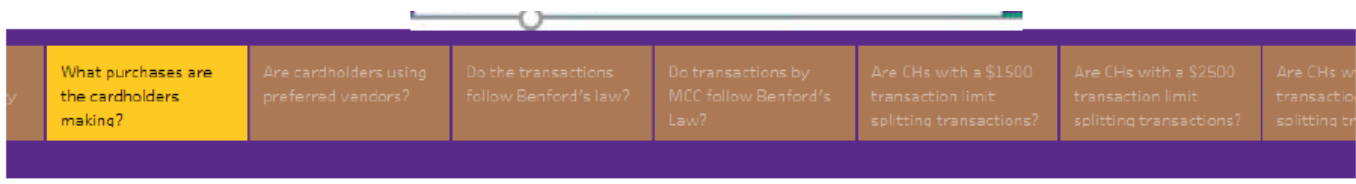

Spend by Cardholder

CH Full Name
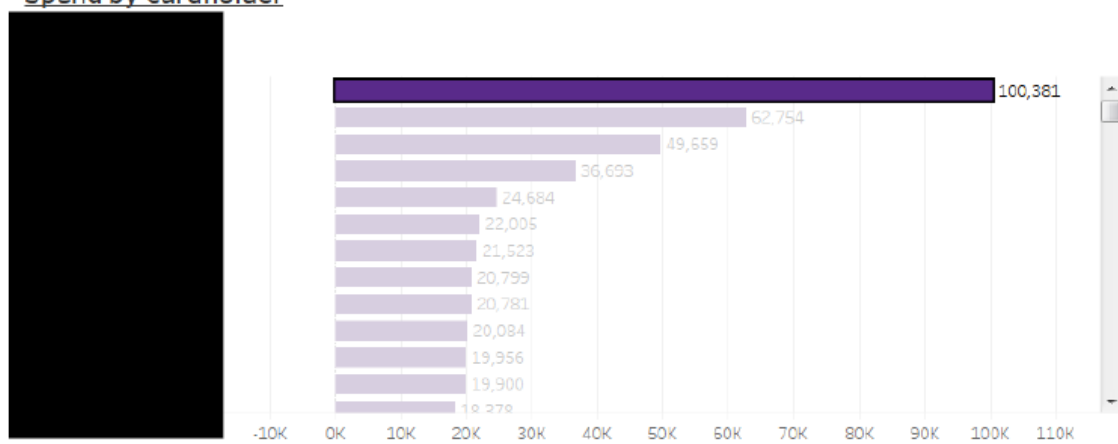

Amount =

Txn Detail

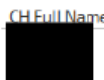

Vendor Na. Txn Number Purchase D. CAMBRIDG.. TXNOOC4240 . 10/13/2017 CHRONICLE.. TXNO04250 . 10/18/2017 GEOLOGICA.. TXNO04245 _. 10/16/2017 HENRY STE. TXNO04252. 10/19/2017 IBISWORLD TXNOC4242. 10/12/2017 INTERNATI.. TXNO04253.. 10/20/2017 MAROUIS...TXNOC4246 10/17/2017 NEWSBANK.. TXNOO4281.. 11/2/2017 ONTHEBOA.. TXNOC4303 . 11/14/2017 PROQUEST TXNO04249.. 10/18/2017 TXNO04291.. 11/7/2017 TXN004293_. 11/7/2017 TXN004293.. 11/8/2017 TXN004295 $\quad 11 / 8 / 2017$

132.00

$8,814.49$ 300.00 $3,675.00$ $18,689.00$ 29.40 $1,395.00$ $9,085.00$ 401.50 $14,330.00$ $1,500.00$ $4,860.00$ $16,000.00$
Googlet Search Images Maps Play YouTubeSigteins

\section{Google carquest}

All Images Videos News

About 2.970,000 results

Any time $\quad$ Carquest Auto Parts $\odot$ - Great poop Past hour httos://Www. carquest.com/ -

Past 24 hours

Past wook

Past month

Past year

CARQUEST works in close partnership with manufacturers and provides products that $m$ specifications and porformance.

\section{Kinston}

Carquest Auto Parts at 809 Mitchell

All results 
Appendix 6. Are cardholders with a $\$ 1500$ transaction limit splitting transactions?

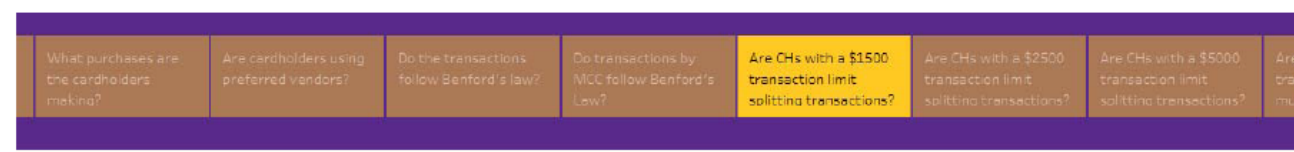

Split Transactions by Cardholder- $\$ 1500$ Single Transaction Limit

If the results are blank, then there were no split transactions for this cardholder profile.

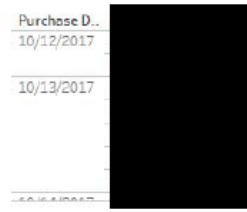

\begin{tabular}{l} 
Vendor Nome Norm \\
NCACPA \\
NCSU SBTDCINT \\
WALMART \\
WALMART \\
HARRIS TEETER \\
WALMMART \\
AMERICANAIRLINES \\
\hline
\end{tabular}

$1500+1500+\square=5$

umber of Records

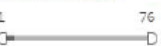

Amount

a

Split Transactions Detail-\$1500 Single

Transaction Limit

Vendor Na..

MARRIOTT

xn Number Purchase D.

HOTELS 


\section{Appendix 7. Are cardholders using preferred vendors?}

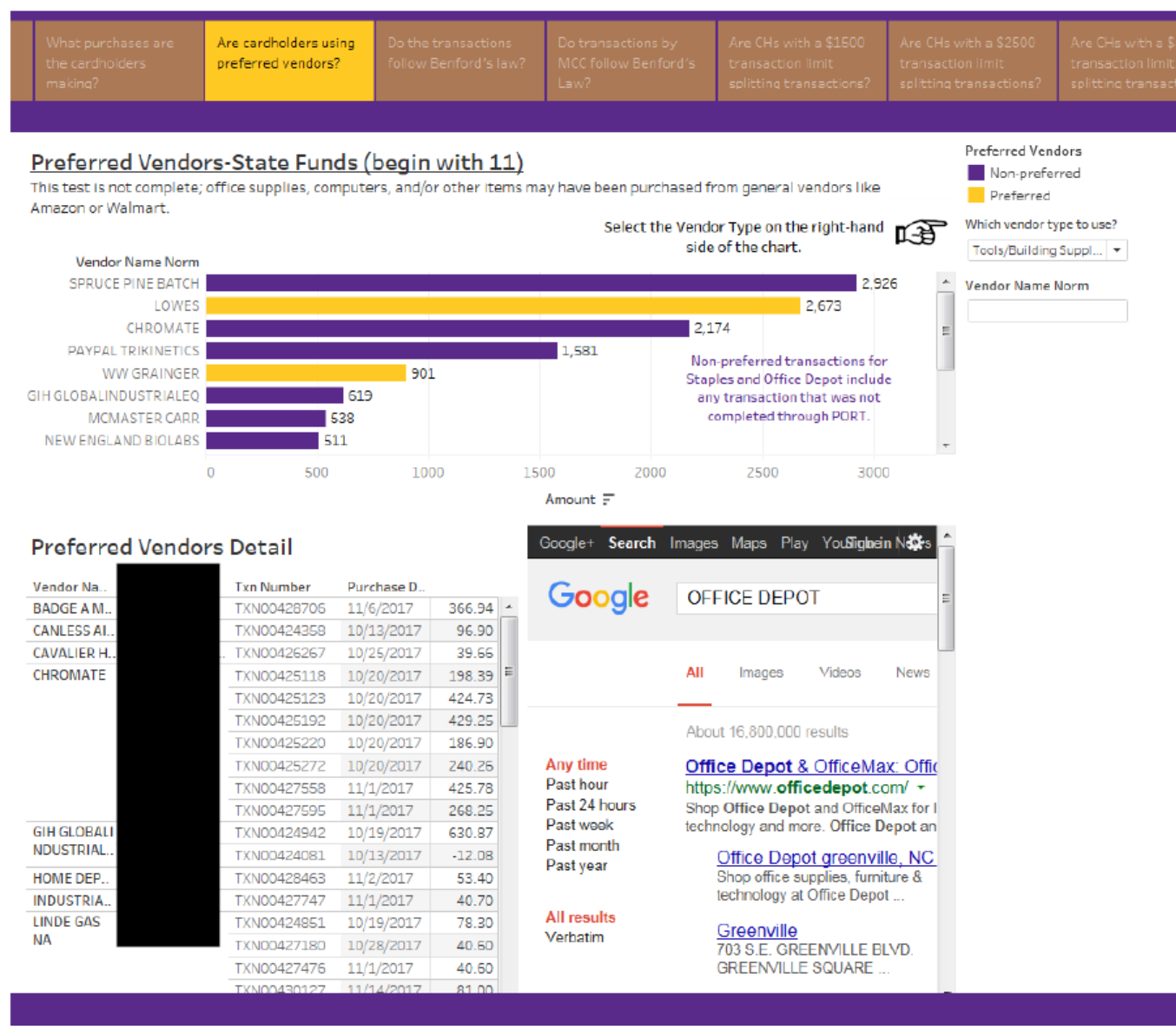




\section{Appendix 8. Do the transactions follow Benford's law?}

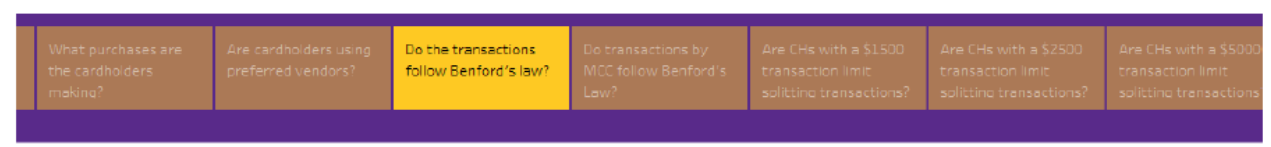

Benford's Law-Leftmost Digit

Benford's law is a mathematical law that states that the leading, or leftmost, digit in many real-life data sources is distributed in a very specific manner.

Specifically, the number 1 occurs as the leading digit about $30 \% 6$ of the time, and as numbers get larger they occur less frequently, with the number 9 occurring less than $5 \%$ of the time. Benford's law can reveal fraudulent information. Click the purple bar to view the transactional details below.

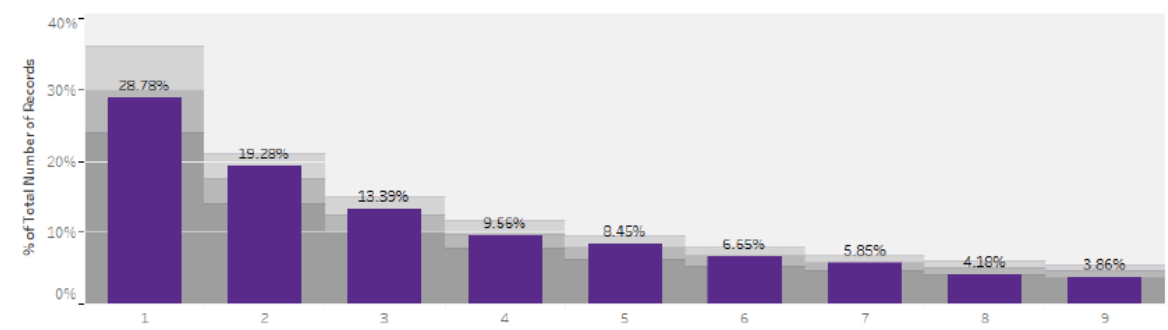

Benford's Law Detail

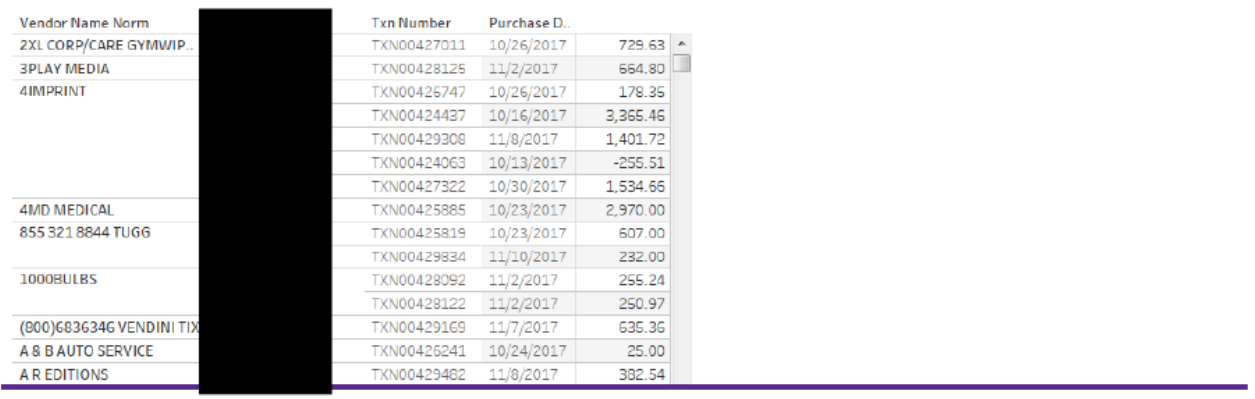




\section{Appendix 9. How are purchases divided amongst the days of the week?}
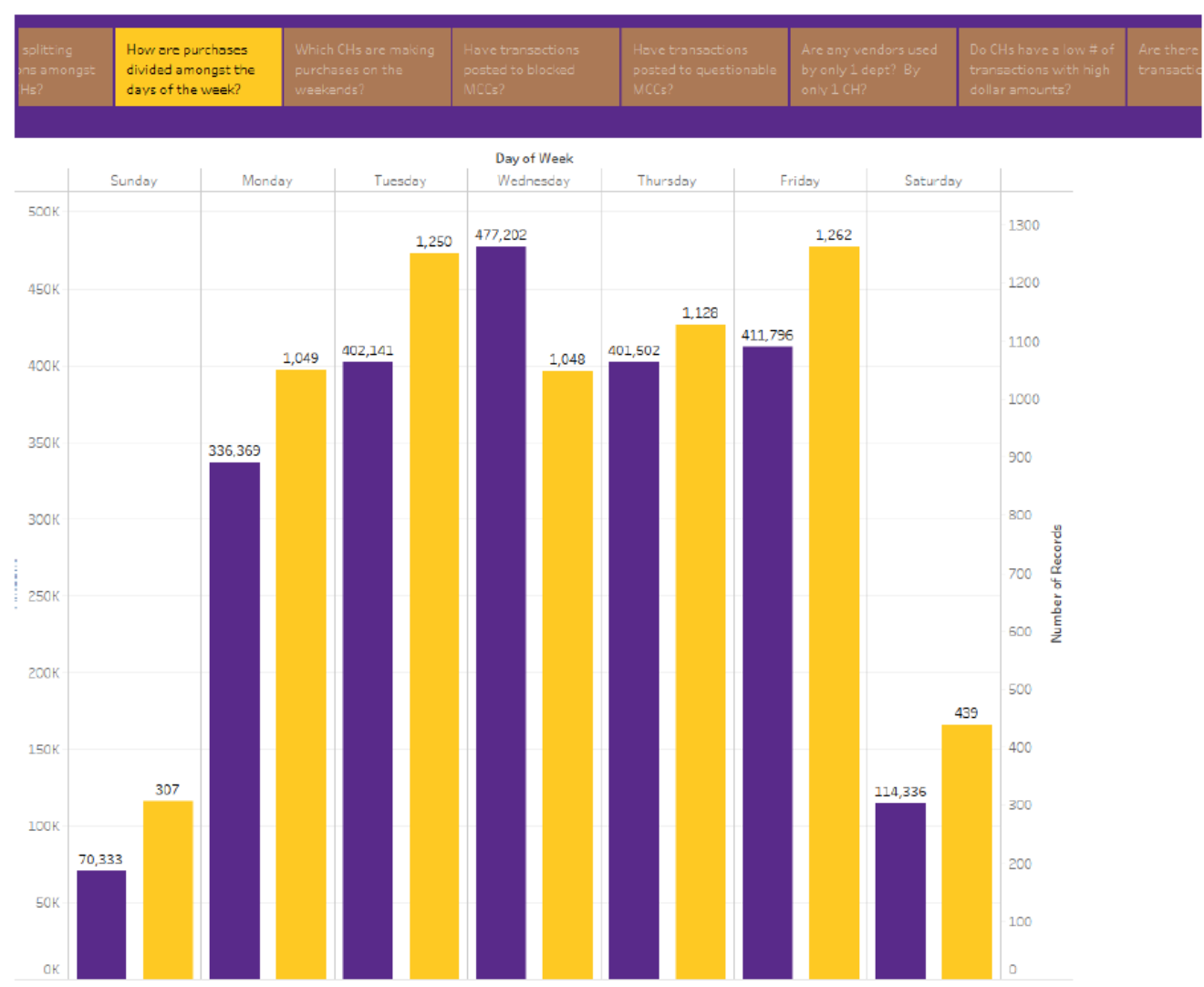
Appendix 10. Which cardholders are making purchases on the weekends?
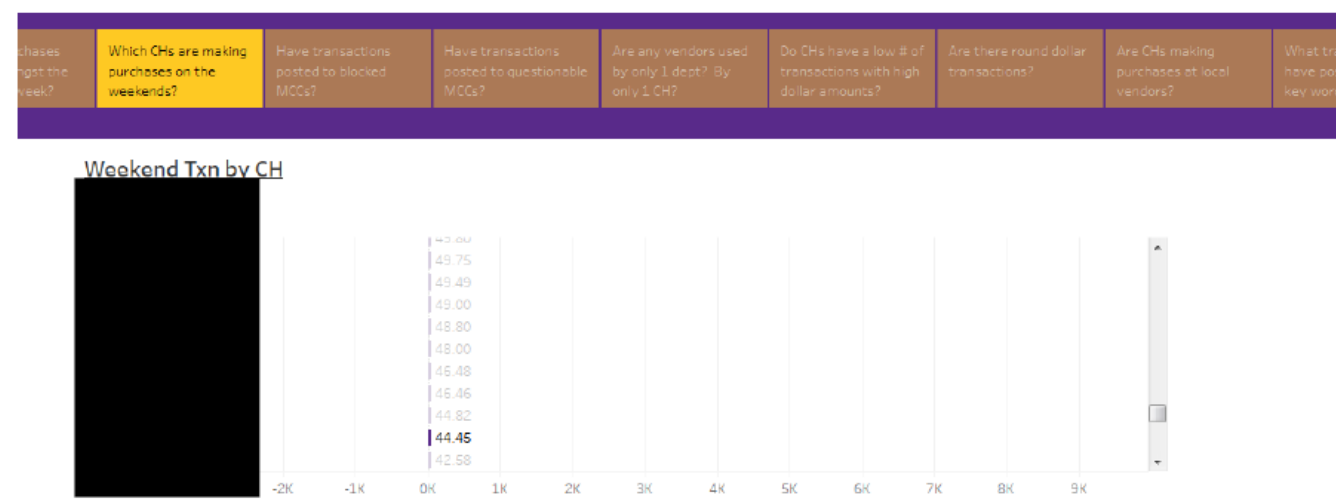

Txn on Weekends Detail

CH Full Name Txn Number Vendor Na. Purchase D.

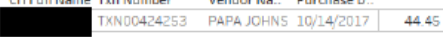




\section{Appendix 11. Have transactions posted to questionable MCCs?}

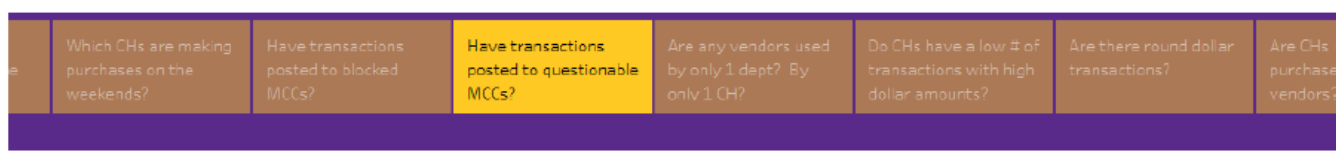

Purchases to Questionable MCCs

MCC Description

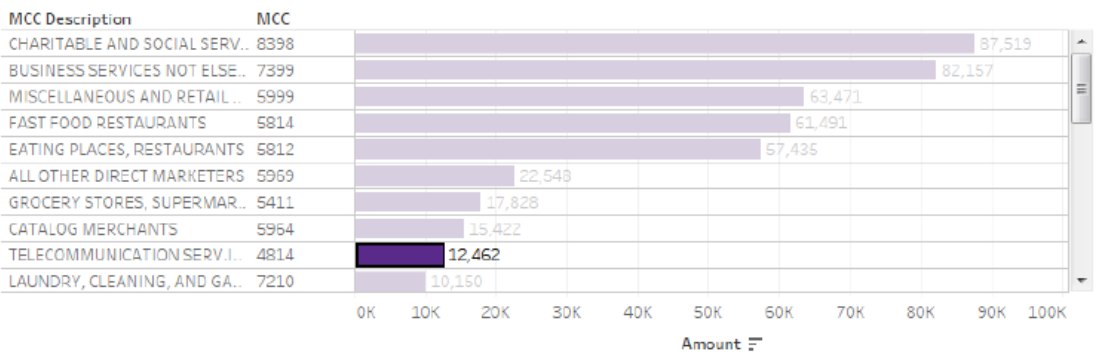

Questionable MCC Detail

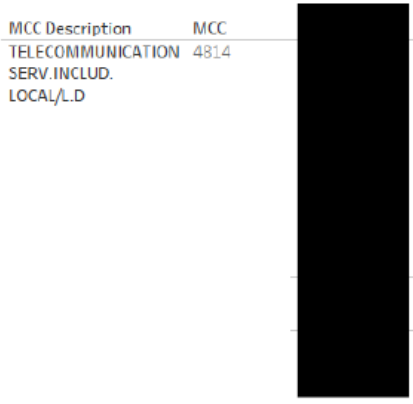

\begin{tabular}{|c|c|c|}
\hline \multirow{2}{*}{$\begin{array}{l}\text { Vendor Name Orio } \\
\text { AT\&T PREMIER EBIL }\end{array}$} & \multicolumn{2}{|l|}{ Txn Number } \\
\hline & TXNO0427110 & $1,511.18$ \\
\hline \multirow[t]{2}{*}{ ATT BILL PAYMENT } & TXNO0425926 & $1,126.36$ \\
\hline & TXNO0 426468 & 471.89 \\
\hline \multirow[t]{3}{*}{ CENTURYLINK/SPEEDPAY } & TXNO0429406 & 175.39 \\
\hline & TXNO0429442 & 105.17 \\
\hline & TXN00430336 & 13.00 \\
\hline USCC CALL CENTER & TXNOD427675 & $4,157.21$ \\
\hline VZWRLLSS IVR VB & TXNOD425225 & 117.55 \\
\hline VZWRLSS MY VZ VB P & TXNO0430171 & 117.55 \\
\hline \multirow[t]{2}{*}{ CENTURYLINK/SPEEDPAY } & TXNO0426153 & $1,882.53$ \\
\hline & TXNO0429568 & 139.71 \\
\hline \multirow[t]{6}{*}{ CENTURYLINK/SPEEDPAY } & TXNO0 425499 & 322.99 \\
\hline & TXNO0425738 & 72.35 \\
\hline & TXNO0426643 & 200.23 \\
\hline & TXNO0426761 & 83.49 \\
\hline & TXNO0426769 & 123.37 \\
\hline & TXNOD429645 & 8894 \\
\hline
\end{tabular}




\section{Appendix 12. Have transactions posted using top keywords?}

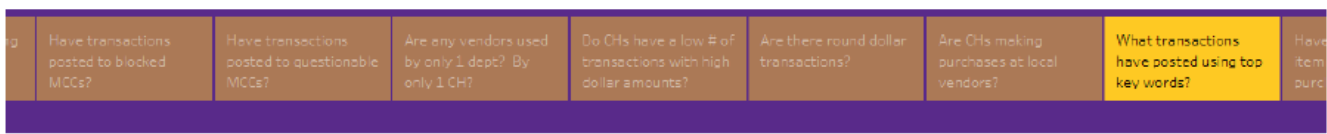

\section{Top Key Words}

If a transaction contains one of these key words, it does not necess arily indicate misuse, fraud and/or abuse. Key words are Items that may be questionable or require further review. If multiplekey words are within the data fields searched, the transaction will be included in only one key word category, not each of the categories.

Top Key Words

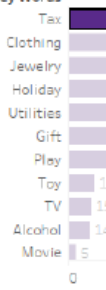

Key Word Detail

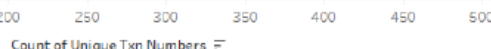

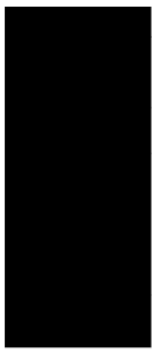

\begin{tabular}{|c|c|}
\hline Vendor Name Norm & \\
\hline DOMINOS PIZZA & \\
\hline GREAT OUTDOOR PROV & \\
\hline DOMINOS PIZZA & \\
\hline JELLY BELLY CANDY CO & \\
\hline MURPHY EXPRESS & \\
\hline SHEETZ & \\
\hline SHELLOIL & \\
\hline WAWA & \\
\hline FOOD UON & \\
\hline JERSEY MIKES & \\
\hline SHELLOIL & \\
\hline
\end{tabular}

\begin{tabular}{|c|c|c|}
\hline Detail Description & Txn Number & Purchase D.. \\
\hline $\operatorname{Tax}$ & TXNO0425691 & $10 / 20 / 2017$ \\
\hline Null & TXNO0426330 & $10 / 25 / 2017$ \\
\hline Card Transaction & TXN00426330 & $10 / 25 / 2017$ \\
\hline Tax & TXN00428372 & $11 / 2 / 2017$ \\
\hline Tax & TXNOOC424424 & $10 / 16 / 2017$ \\
\hline \multirow[t]{3}{*}{ Tax } & TXNO0428649 & $11 / 2 / 2017$ \\
\hline & TXNOOL28800 & $11 / 5 / 2017$ \\
\hline & TXNO0429270 & $11 / 7 / 2017$ \\
\hline $\operatorname{Tax}$ & TXNO0424598 & $10 / 17 / 2017$ \\
\hline $\operatorname{Tax}$ & TXNOO427974 & $11 / 1 / 2017$ \\
\hline $\operatorname{Tax}$ & TXNOD427142 & $10 / 29 / 2017$ \\
\hline Tax & TXN00426905 & $10 / 28 / 2017$ \\
\hline Tax & TXNOC426910 & $10 / 27 / 2017$ \\
\hline \multirow[t]{2}{*}{ Tax } & TXN00425714 & $10 / 20 / 2017$ \\
\hline & 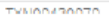 & 11/19/9M17 \\
\hline
\end{tabular}

Top Key Words

(AII)

$\checkmark$ Alcohol

$\checkmark$ Clothing

Cansultent

$\checkmark$ Gift

(1) Holiday

Insurance

$\checkmark$ Jewelry

$\square$ Movie

Not a Top Concern

(V) Play

[1] Tax

$\checkmark$ Toy

$\checkmark$ Utilities

- Purchase Date

$1 / 28 / 2016 \quad 11 / 15 / 2017$

C $D$ 


\section{Appendix 13. Have questionable items been posted?}

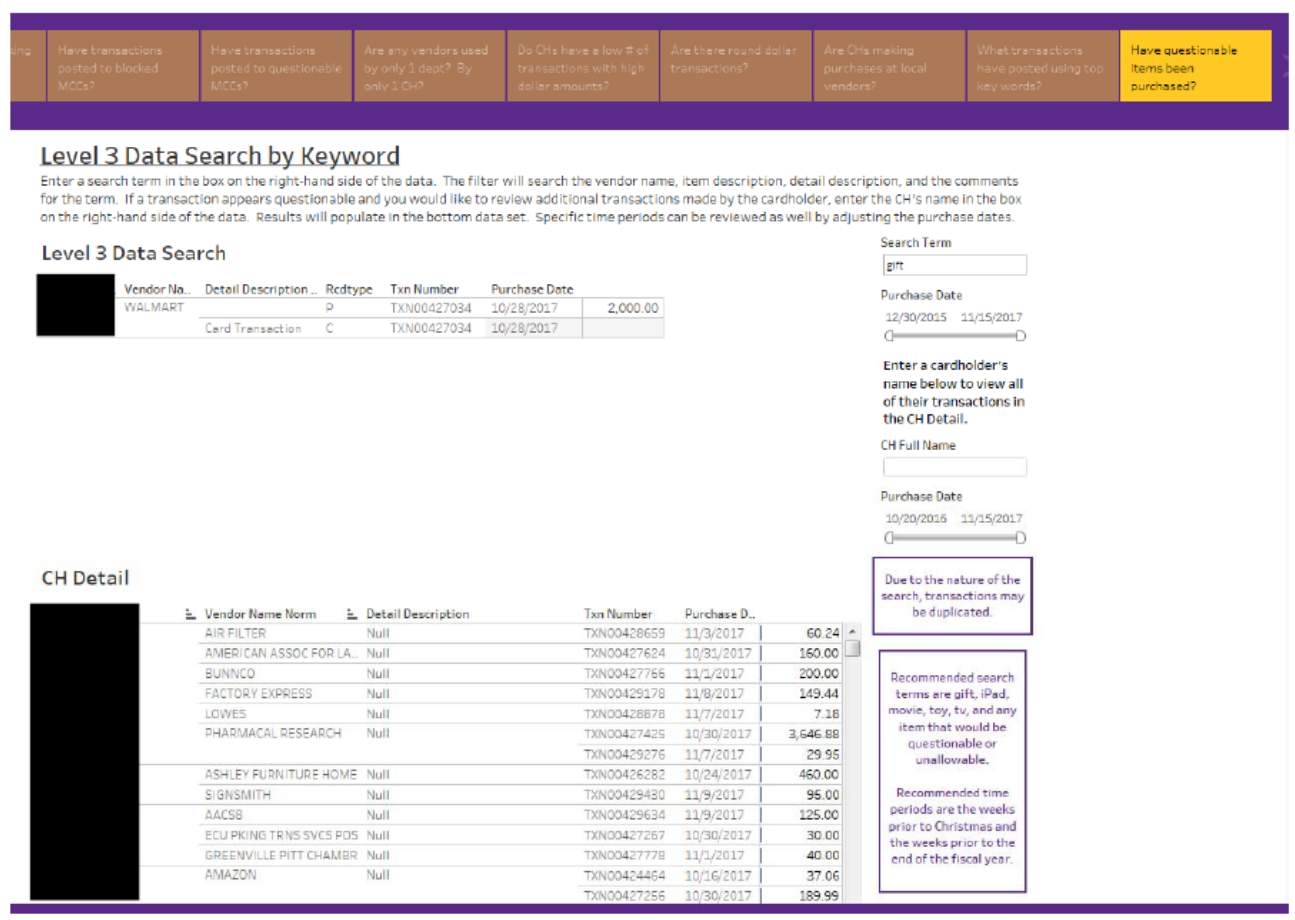




\section{Appendix 14. Roles and responsibilities of each department}

\begin{tabular}{|c|c|c|}
\hline Internal Audit & Materials Management & Information Technology \\
\hline $\begin{array}{l}\text { (Monthly) Will pull the ProCard }{ }^{\mathrm{TM}} \\
\text { transactional data from Works }{ }^{\circledR} \text {. }\end{array}$ & $\begin{array}{l}\text { (Monthly) Will access and save the } \\
\text { Tableau® packaged workbook } \\
\text { when notified that it is available }\end{array}$ & $\begin{array}{l}\text { (Monthly) Will maintain the } \\
\text { recurring running script that looks } \\
\text { in the agreed-upon drop off folder } \\
\text { on PirateDrive, picks up data file if } \\
\text { present, and alters the data file as } \\
\text { follows: } \\
\text { - Runs SQL to perform vendor } \\
\text { normalization } \\
\text { - Runs SQL to parse out the } \\
\text { "Parent" and "Child" } \\
\text { transactions } \\
\text { - DOES NOT make any other } \\
\text { changes to the format, content, } \\
\text { field formatting, etc. to the } \\
\text { data. Making such changes can } \\
\text { affect the way Tableau } \\
\text { recognizes the data and } \\
\text { performs the analytics. All data } \\
\text { fields must remain exactly as } \\
\text { they were when picked up by } \\
\text { the ITCS program. }\end{array}$ \\
\hline $\begin{array}{l}\text { (Monthly) Will place the raw data } \\
\text { in the agreed-upon drop off folder } \\
\text { on PirateDrive for IT routine to } \\
\text { pick up, scrub and return to IA. }\end{array}$ & $\begin{array}{l}\text { (Monthly) Will review the Tableau } \\
\text { packaged workbook, review the } \\
\text { results, and conduct and document } \\
\text { audit processes as normal (using } \\
\text { this new tool instead of the } \\
\text { previously relied upon reports and } \\
\text { techniques) }\end{array}$ & $\begin{array}{l}\text { (Recurring/as needed) Will work } \\
\text { with Internal Audit to resolve any } \\
\text { problems with the program, or to } \\
\text { make any necessary changes to the } \\
\text { vendor normalization and } \\
\text { Parent/Child programming logic }\end{array}$ \\
\hline $\begin{array}{l}\text { (Monthly) Will connect the Tableau } \\
\text { workbook to the new data, perform } \\
\text { high-level spot checks to be sure } \\
\text { the data is being read correctly by } \\
\text { Tableau, package the workbook. }\end{array}$ & $\begin{array}{l}\text { Contact Internal Audit with any } \\
\text { problems or questions about the } \\
\text { Tableau workbook, desired } \\
\text { changes, etc. }\end{array}$ & \\
\hline $\begin{array}{l}\text { (Recurring) Will receive input from } \\
\text { Materials Management regarding } \\
\text { any problems with the data or with } \\
\text { the Tableau analysis of the data; } \\
\text { will resolve Tableau problems and } \\
\text { requests with Materials } \\
\text { Management. }\end{array}$ & & \\
\hline
\end{tabular}




\section{Appendix 15. Email from University compliance officer regarding the continuous monitoring tool.}

"I have retired my other split reports that I had to manually configure and drill into. That has saved me a substantial amount of time and I am very thankful. Like I said, if there could be a way to export to Excel, it would be my favorite even more. Maybe a future release?

I thought we'd like the weekend report more, however a lot of them have to deal with when the vendors are charging the cards and employees on travel. I have focused more on looking into store front locations (Target, Walmart, etc.) for these types of transactions. If I see anything odd, I'll definitely bring to your attention.

It's interesting, but I've found that people seem to be less productive on Mondays and Tuesdays, as far as purchasing goes.

The preferred vendor tabs is one of my favorites as well, because I can easily pin point the cardholders I need to email regarding State Contracts and I can send a mass email. Now, if I can convince someone on my team that we don't have to look at every single individual transaction, I'll be onto something! Old habits die hard, but we're getting there.

Benford's law has been really interesting in "real-life" action.

The questionable items tab has helped me with matching up some items." 